\title{
COMPETÊNCIA TRADUTÓRIA E FORMAÇÃO POR COMPETÊNCIAS ${ }^{1}$
}

\author{
Amparo Hurtado Albir 1 \\ 느niversidade Autônoma de Barcelona, Barcelona, Espanha \\ Tradução de: Lavínia Teixeira Gomes ${ }^{2}$ \\ Marta Pragana Dantas 2 \\ ${ }^{2}$ Universidade Federal da Paraíba, João Pessoa, Paraíba, Brasil
}

\begin{abstract}
Resumo: O objetivo deste artigo é estabelecer as bases de um desenho curricular por competências na formação de tradutores, que exemplificamos a partir da disciplina de Introdução à Tradução (para a língua materna). Para tanto, situamos, por um lado, os desafios atuais postos pelo desenho curricular e as necessidades pedagógicas daí decorrentes, e, por outro, expomos os fundamentos da formação por competências e as características da competência tradutória. Propomos, em seguida, as bases de um desenho curricular por competências e tarefas de tradução na formação de tradutores: o arcabouço teórico, as categorias de competências específicas, a operacionalização das competências, o sequenciamento, a elaboração da unidade didática e a avaliação.

Palavras-chave: Desenho Curricular; Formação por Competências; Competência Tradutória; Didática da Tradução; Enfoque por Tarefas de Tradução
\end{abstract}

$1 \mathrm{~N}$. das T. : artigo publicado originalmente em língua francesa na revista TTR: traduction, terminologie, rédaction, em 2008. Agradecemos expressamente à autora Amparo Hurtado Albir e à revista TTR por nos conceder a autorização para traduzir e publicar este artigo em português. Referência bibliográfica completa do artigo original: Hurtado Albir, A. "Compétence en traduction et formation par compétences". TTR : traduction, terminologie, rédaction. La formation en traduction: pédagogie, docimologie, technologies, 21/1, 2008, p. 17-64. 


\title{
TRANSLATION SKILLS AND SKILLS TRAINING
}

\begin{abstract}
The aim of this article is to establish guidelines for a skillbased curriculum in translator training through introduction to translation (into the mother tongue). I begin by describing the current challenges that arise from curriculum development, together with the pedagogical needs they entail, before going on to explain the basics of skill-based training and the characteristics of translation proficiency. I propose a skill and translation task-based approach for translator training, which includes the following: theoretical framework; categories of specific competences; operationalization of competences; sequencing; development of teaching units; and assessment.
\end{abstract}

Keywords: Curriculum Design; Competence-based Training; Translation Competence; Translation Teaching; Translation Taskbased Approach

\section{Desafios pedagógicos e sociais para o desenho curricular. O perfil profissional}

Atualmente, todo desenho curricular deve enfrentar, a nosso ver, três grandes tipos de desafios:

1. Adequação do ensino a um modelo passível de homologação e reconhecimento no plano internacional, capaz de responder às exigências decorrentes da crescente mobilidade dos estudantes, professores e profissionais. Essa exigência é particularmente importante no caso da tradução, pois, dada a mundialização do mercado de trabalho, existe uma grande mobilidade universitária e profissional. Ademais, ela é indispensável no contexto europeu, no âmbito da criação de um Espaço Europeu do Ensino Superior (EEES).

2. Adequação do ensino a um modelo apropriado às demandas sociais e às condições exigidas no mundo do trabalho.

3. Adequação do ensino aos novos modelos pedagógicos. 
O primeiro desafio requer um esforço de clareza e de unificação de critérios no desenho dos currículos. Os dois outros demandam uma renovação pedagógica e que sejam consideradas as necessidades sociais e profissionais.

\subsection{Desafios pedagógicos}

Ao que nos parece, os desafios pedagógicos atuais podem ser resumidos em três princípios essenciais:

1. Aprender fazendo. Esse princípio, que não é novo, foi atribuído a Confúcio: "Contaram-me e esqueci. Vi e entendi. Fiz e aprendi". Ou seja, retemos melhor o que fazemos, aprendemos melhor quando se trata de uma aprendizagem ativa. Aprender fazendo é um princípio-chave da pedagogia moderna.

2. Aprender a percorrer processos. Esse princípio foi formulado em nossa disciplina ${ }^{2}$ há quase 30 anos, de maneira magistral, por Delisle, pioneiro de uma nova didática da tradução de orientação cognitivo-construtivista: "Ensinar a traduzir é fazer compreender o processo intelectual pelo qual uma dada mensagem é transposta em uma outra língua, colocando o aprendiz-tradutor no cerne da operação tradutória para fazê -lo apreender sua dinâmica" (Delisle (a) 16).

3. Aprender de uma maneira holística. Compartilhamos a crítica que Escotet faz ao ensino universitário atual, quando afirma que tal ensino segue padrões típicos do passado e que o currículo é concebido de forma unidisciplinar: "[...] uma das características marcantes do ensino universitário atual reside no fato de ainda seguir padrões típicos da primeira revolução industrial e do início do século XX. O currículo

${ }^{2} \mathrm{~N}$. das T.: notre discipline no texto original refere-se ao campo disciplinar da Tradutologia. Sobre a emergência do termo Traductologie e sua utilização, ver nota 7. 
é concebido de maneira unidisciplinar ou, no melhor dos casos, pluridisciplinar" (Escotet 31$)^{3}$.

O autor tem razão, pois não se trata somente de formar profissionais, mas de formar indivíduos, indivíduos capazes de aprender a aprender, comunicar, cooperar, ter empatia, ser críticos, se automotivarem, construir seus conhecimentos de maneira autônoma. A importância, portanto, de adquirir capacidades afetivas, relacionais e comportamentais, o manuseio de instrumentos de informação, etc.

\subsection{Desafios sociais}

É igualmente necessário responder aos novos desafios sociais. Desse ponto de vista, trata-se de implantar uma formação que desenvolva as competências necessárias para agir no mundo do trabalho e que garanta uma aprendizagem autônoma, polivalente e permanente, capaz de se adaptar a um mercado mundializado e em constante mudança.

Dessa forma, utiliza-se na esfera do trabalho a noção de "competências profissionais". As competências profissionais correspondem a uma noção da psicologia do trabalho utilizada na área dos recursos humanos por diferentes autores (McClelland; Boyatzis (a), (b); Spencer; McClelland and Spencer). O pioneiro foi McClelland (1973), que tentou mostrar que os antecedentes universitários dos indivíduos e os testes de inteligência não permitem, por si sós, prever uma boa prática profissional. Fala-se, desse modo, de um modelo de gestão por competências dos recursos humanos.

Houve várias definições da competência profissional. Citemos, por exemplo, a de Dirube, que resume bem os traços da competência profissional:

3 No original: “[...] una de las cosas más representativas de la enseñanza universitaria actual es el estar apegada a esquemas propios de la revolución industrial del pasado y de comienzos del siglo XX. El currículo está concebido de forma unidisciplinaria o en el mejor de los casos pluridisciplinaria".

Cad. Trad., Florianópolis, v. 40, n⿳0 1, p. 367-416, jan-abr, 2020. 
Características que possuem certas pessoas e que fazem com que seu comportamento seja especialmente satisfatório na empresa ou na organização da qual fazem parte. As competências dizem respeito ao comportamento e se manifestam através da conduta; elas são, portanto, um conjunto de conhecimentos, habilidades, valores, hábitos e motivações (Dirube 98) ${ }^{4}$.

A competência profissional é, dessa forma, considerada como um saber-fazer ${ }^{5}$ complexo (conhecimentos, habilidades, atitudes, valores, etc.) que garante a eficácia de um exercício profissional. Isso evidencia a importância de se definirem as competências profissionais como ponto de partida para a elaboração dos currículos: o perfil profissional.

\section{$1.3 \mathrm{O}$ perfil profissional}

De acordo com Yániz e Villardón (2006), o perfil profissional define a identidade profissional dos indivíduos que realizam um dado trabalho e explica as principais funções executadas nessa profissão, assim como as tarefas mais comuns. Nesse sentido, o perfil profissional é definido a partir dos conhecimentos e habilidades específicos relacionados às práticas profissionais mais comuns que lhe dizem respeito. Cabe ressaltar que se trata de partir de práticas profissionais bem sucedidas, assim como das práticas dominantes e emergentes.

\footnotetext{
${ }^{4}$ No original: "Las características que tienen determinadas personas que hacen que su comportamiento sea especialmente satisfactorio en el entorno empresarial $u$ organizativo en el cual se desenvuelven. Al referirse al comportamiento, al manifestarse a través de la conducta, las competencias son un compendio de conocimientos, destrezas, valores, hábitos e motivos".

${ }^{5} \mathrm{~N}$. das T.: mesmo estando o termo dicionarizado no português do Brasil, traduzimos savoir-faire (saber-fazer) a fim de manter a coerência do campo lexical em relação aos diversos saberes e conhecimentos mencionados pela autora ao longo do artigo: saber-fazer, saber-agir, saber-ser, saber o quê, saber como.
} 
O fato de o perfil profissional constituir o ponto de partida para o desenho curricular é muito importante em formações que, como a nossa, levam a uma inserção no mundo do trabalho. Partir das práticas profissionais bem sucedidas e das práticas dominantes e emergentes é igualmente essencial em Tradutologia ${ }^{6}$, em que o mundo do trabalho está em mudança constante.

Yániz e Villardón resumem muito bem o papel do perfil profissional no desenho curricular, na figura abaixo ${ }^{7}$ :

${ }^{6}$ N. das T.: O termo Traductologie é geralmente empregado como o equivalente em francês para Translation Studies em inglês, expressão cunhada por James Holmes em 1972 (no artigo The Name and Nature of Translation Studies) para definir e caracterizar uma disciplina teórica nascida nos anos 1960 e reivindicar sua autonomia. Já o termo Traductologie foi primeiramente usado em 1968 por um grupo de pesquisadores belgas (R. Goffin, P. Hurbin e J.-M. Van der Meerschen). Mas é somente em 1973, com Brian Harris (que batizou o termo no Canadá e criou seu equivalente em inglês, Translatology) e Jean-René Ladmiral (França), que sua utilização se difunde na comunidade científica de vários países, entre os quais Bélgica, Suíça, Itália e Espanha. No Brasil, o uso de Translation Studies ou Estudos da Tradução consagrou-se entre a maioria dos pesquisadores da área. Em seus trabalhos, ainda que Hurtado Albir defina Traductología em sentido bastante próximo ao de Translation Studies de Holmes, ela reformula o modelo proposto pelo autor para descrição da disciplina, por ver em determinados aspectos da proposta certa confusão e rigidez. Por essa razão, optamos por manter a forma Tradutologia na tradução, ainda que menos usada no Brasil. (Fontes: Harris, B. What I really meant by "Translatology". TTR: traduction, terminologie, rédaction, 1, 2, p. 91-96, 1988; Hurtado Albir, A. Perspectivas de los Estudios sobre la traducción. In: Hurtado Albir (Ed.). Estudis sobre la traducció. Castelló de la Plana: Universitat Jaume I, 1994, p. 25-41; Oustinoff, M. Les "Translation Studies” et le tournant traductologique. Hermès, 49, p. 21-28, 2007).

${ }^{7}$ Figura original em espanhol. 


\section{Figura 1: O perfil profissional}

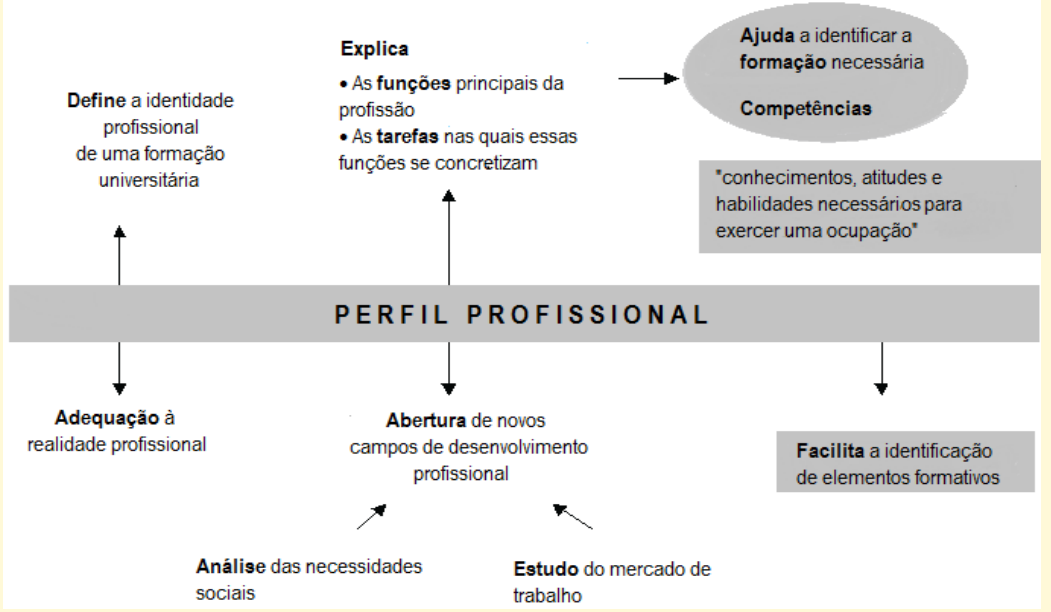

Fonte: (Yániz and Villardón 20)

De acordo com essa figura, é o perfil profissional que define a identidade profissional de uma formação universitária e que garante uma adequação à realidade profissional. Esse perfil profissional explica as principais funções de uma profissão e as tarefas nas quais essas funções se concretizam; para tanto, é necessário analisar as necessidades sociais e realizar um estudo do mercado de trabalho, a fim de conhecer os novos campos de desenvolvimento profissional (as práticas emergentes). Essa definição do perfil profissional ajuda a identificar a formação necessária, isto é, as competências necessárias que facilitam, por sua vez, a identificação dos elementos formativos.

\section{A formação por competências (FPC)}

No contexto de renovação pedagógica dos últimos anos, surgiu um novo modelo pedagógico que alguns chamam de "formação por competências" (FPC). 


\subsection{O que é uma competência?}

Há diferentes definições de competência. Lasnier (2000) propõe a seguinte definição:

Uma competência é um saber-agir complexo resultante da integração, mobilização e organização de um conjunto de capacidades e habilidades (podendo ser de ordem cognitiva, afetiva, psicomotora ou social) e conhecimentos (conhecimentos declarativos) utilizados eficazmente, em situações que possuem características em comum (Lasnier 32).

Yániz e Villardón (2006), por sua vez, definem a competência nos seguintes termos:

Uma competência é o conjunto de conhecimentos, habilidades e atitudes necessários para exercer uma dada ocupação e a capacidade de mobilizar e aplicar esses recursos em um determinado ambiente, para produzir um resultado definido. (Yániz e Villardón 23) .

Essas definições da competência evidenciam três aspectos: saber-agir, integração e contexto.

Definir a competência como um saber-agir implica, primeiramente, que ela não é um simples saber-fazer e que não se reduz a conhecimentos operacionais. Isso implica, em seguida, que todo saber-fazer só pode ser adquirido pela prática. Por fim, saber-agir significa que não se trata somente de aplicar saberes, mas de aplicá-los de modo eficaz.

${ }^{8}$ No original: "Una competencia es el conjunto de conocimientos, habilidades y actitudes necesarios para desempeñar una ocupación dada y la capacidad de movilizar y aplicar estos recursos en un entorno determinado, para producir un resultado definido". 
Uma competência é, além disso, uma integração de diferentes tipos de capacidades e habilidades (cognitivas, afetivas, psicomotoras ou sociais) e conhecimentos declarativos (saber o quê). Dessa forma, pode-se dizer que a competência integra um saber (um conjunto de conhecimentos específicos de uma disciplina), um saberfazer (habilidades para resolver problemas práticos), bem como um saber-ser (habilidades de tipo afetivo e social). Em outras palavras, uma competência é, ao mesmo tempo, um saber, um poder e um querer.

E por fim, cabe considerar que uma competência somente é adquirida quando se é capaz de utilizá-la de uma maneira eficaz em um dado contexto.

\subsection{Competências específicas e competências gerais}

A FPC faz a distinção entre competências específicas (ou disciplinares) e competências gerais (ou transversais). As competências específicas são aquelas próprias a cada disciplina e que definem um determinado perfil profissional; são formuladas a partir dos conhecimentos e habilidades específicos das práticas profissionais mais comuns desse perfil: as práticas profissionais bem sucedidas, dominantes e emergentes. As competências gerais, por sua vez, aplicam-se a todas as disciplinas. Esses dois tipos de competências não são isolados um do outro, mas, bem ao contrário, existe entre eles um continuum. Nesse sentido, cada disciplina deve determinar, em função do perfil profissional que a caracteriza, quais são as competências gerais e específicas que definem esse perfil.

No que diz respeito às competências gerais, pode-se citar o Projeto Tuning (Tuning Educational Structures in Europe), realizado de 2000 a 2004 (González; Wagenaar, 2003). Trata-se de um projeto sobre as estruturas educativas e currículos no âmbito da reforma do ensino superior na Europa, coordenado pelas Universidades de Deusto (Espanha) e de Groningen (Holanda). Um questionário foi elaborado e dele participaram vários especialistas de 135 centros europeus de ensino superior de 27 países. As competências 
propostas no questionário (30 no total) coincidem com as que foram selecionadas por várias universidades europeias.

O projeto Tuning propõe três tipos de competências gerais: competências instrumentais, competências interpessoais e competências sistêmicas (González; Wagenaar 70). As competências instrumentais são um instrumento para atingir um objetivo; elas podem ser de tipo cognitivo, metodológico, tecnológico e linguístico. As competências interpessoais incluem habilidades de interação com o outro; elas favorecem os processos de interação social e a comunicação. As competências sistêmicas representam uma combinação de compreensão, sensibilidade e conhecimentos para possibilitar ao indivíduo compreender como as partes de um todo estão relacionadas entre si.

\section{Quadro 1: Competências gerais segundo o projeto Tuning}

\begin{tabular}{|l|l|l|}
\hline COMPETÊNCIAS & COMPETÊNCIAS & COMPETÊNCIAS \\
INSTRUMENTAIS & INTERPESSOAIS & SISTÊMICAS \\
\hline - capacidade de análise e síntese & - capacidade de crítica e & - capacidade de aplicar os \\
- capacidade de organização e & autocrítica & conhecimentos na prática \\
planejamento & - trabalho em equipe & - habilidades de pesquisa \\
- conhecimento geral de base & - habilidades interpessoais & - capacidade de aprendizagem \\
- aprofundamento do & - capacidade de trabalho em & - capacidade de adaptação a \\
conhecimento de base da & uma equipe interdisciplinar & novas situações \\
profissão & - capacidade de se comunicar & - capacidade de gerar novas \\
- comunicação oral e escrita em & com especialistas de outras & ideias (criatividade) \\
língua materna & disciplinas & - leadership \\
- conhecimento de uma língua & - apreciação da diversidade e & - compreensão de culturas e \\
segunda & da multiculturalidade & hábitos de outros países \\
- habilidades de base em & - capacidade de trabalhar em & - capacidade de trabalho \\
informática & um contexto internacional & autônomo \\
- habilidades de gestão da & - comportamento ético & - concepção e gestão de projetos \\
informação & & - espírito de iniciativa e de \\
- resolução de problemas & & empreendimento \\
- tomada de decisões & & - preocupação com a qualidade \\
& & \\
\end{tabular}

Fonte: (González and Wagenaar 72-3) 


\subsection{Fundamentos e princípios da Formação por competências}

Como Lasnier (2000) observa, a FPC é "uma sequência lógica" da Formação por objetivos de aprendizagem (22), desenvolvida a partir dos anos 1960. Os aspectos destacados pela FPC em relação à etapa anterior são:

- mais transparência dos perfis profissionais nos programas de estudo;

- mais repercussão sobre os resultados da aprendizagem;

- mais flexibilidade do desenho curricular;

- mais integração de todos os aspectos curriculares.

Na FPC, as competências são o fio condutor do desenho curricular: os objetivos de aprendizagem são definidos em termos de competências, e é a partir das competências que os conteúdos são assimilados, que é feito o sequenciamento em unidades didáticas e são elaboradas as atividades de aprendizagem e a avaliação. Nesse sentido, a FPC preconiza um modelo integrado de ensino, aprendizagem e avaliação que confira uma importância considerável à avaliação formativa e que conte com propostas pedagógicas anteriores, tais como a aprendizagem cooperativa, a aprendizagem por problemas, o enfoque por tarefas e projetos, etc.

Os fundamentos da FPC encontram-se nas teorias da aprendizagem cognitivo-construtivistas e socioconstrutivistas, e se alimentam das pesquisas realizadas nos últimos vinte anos, para obter uma aprendizagem mais significativa junto ao estudante. Segundo Lasnier (158), os princípios próprios da FPC são:

- Globalidade. Trata-se de uma abordagem global que concebe a competência como um todo e preconiza tarefas globais (integralizadoras);

- Construção. Favorecem-se a ativação de aquisições prévias e a elaboração de novas aprendizagens; 
- Alternância. Produzem-se alternâncias do global ao específico e do específico ao global;

- Aplicação. É uma aprendizagem centrada sobre o agir;

- Distinção. Distinguem-se conteúdo e processo;

- Significação. Propõem-se situações autênticas e motivadoras para os estudantes;

- Coerência. Estabelece-se uma coerência entre o ensino, a aprendizagem, a avaliação e as competências;

- Integração. Considera-se que todos os elementos do processo de aprendizagem estão relacionados entre si e à competência; o aprendiz desenvolve a competência utilizando os componentes de forma integrada;

- Iteração. Submete-se várias vezes o estudante a um mesmo tipo de tarefa ligada a uma competência e a um mesmo conteúdo disciplinar;

- Transferência. Produzem-se transferências entre tarefas e contextos, favorecendo a utilização de conhecimentos e capacidades aprendidas em outros contextos.

Todos esses princípios estão ligados e agem em conjunto. A integração é o princípio-chave da FPC, para onde todos os outros convergem. Trata-se de uma tripla integração: integração dos componentes que constituem cada competência; integração das diferentes competências que definem um perfil; integração das atividades de ensino, aprendizagem e avaliação.

\section{A competência tradutória e o perfil profissional}

Já indicamos a importância de se partir do perfil profissional para o desenho curricular ( $c f$. supra 1.3). Para determinar quais são as competências específicas da didática da tradução, convém, portanto, em primeiro lugar, determinar aquelas que caracterizam o perfil do tradutor profissional: a competência tradutória $(\mathrm{CT})^{9}$.

${ }^{9}$ As questões relativas à competência tradutória e sua aquisição foram desenvolvidas 


\subsection{A competência tradutória}

Em Tradutologia, não existe uma tradição de pesquisa sobre a CT comparável, por exemplo, à pesquisa relativa à competência comunicativa em linguística aplicada. $\mathrm{O}$ termo começou a ser utilizado em meados dos anos 1980 e, mesmo que muito poucos estudos específicos tenham sido realizados, nos anos 1990 diversas propostas foram feitas sobre o seu funcionamento. Grande parte das propostas são modelos centrados na descrição dos componentes da CT. É o caso das propostas de Bell (1991), Kiraly (a), Presas (1996), Hurtado Albir (c), Hansen (1997), Risku (1998), Neubert (2000), Kelly (a), Gonçalves ((a), (b)), etc. Existem também propostas sobre o funcionamento específico da CT em tradução para a língua estrangeira (Beeby; Campbell; Martínez Mélis).

Entretanto, não existe estudo empírico sobre a CT como um todo $^{10}$. É justamente o objetivo do grupo PACTE ${ }^{11}$ : desenvolver uma pesquisa empírico-experimental sobre a $\mathrm{CT}$ e sua aquisição (cf. PACTE, (b), (c), (d), (e), (f), (g)).

A primeira versão de nosso modelo holístico de CT foi apresentada em 1998 (PACTE, (a), (b)). Em 2000, após um estudo exploratório, revisamos esse modelo (PACTE, (d)). De acordo com esse modelo, a CT é o sistema subjacente de conhecimentos declarativos e essencialmente operacionais, necessários para traduzir. A CT possui, além disso, quatro particularidades: (1) é um conhecimento especializado que nem todos os bilíngues possuem; (2) é um conhecimento essencialmente operacional, e não [essencialmente] ${ }^{12}$

mais amplamente por Hurtado Albir (376-408).

${ }^{10}$ Orozco (113) observa que existem somente dois ensaios parciais de operacionalização da CT: Lowe (1987), e Stansfield, Scott e Kenyon (1992).

${ }^{11}$ O grupo de pesquisa PACTE é formado atualmente [em 2008] por A. Beeby, M Fernández, O. Fox, A. Hurtado Albir, I. Kozlova, A. Kuznik, W. Neunzig, P. Rodríguez e L. Romero. N. das T.: as informações sobre os membros atuais do PACTE estão disponíveis na página oficial do grupo: < http://grupsderecerca. uab.cat/pacte/es/content/miembros-actuales $>$.

${ }^{12}$ N. das T.: termo inserido com a anuência da autora. 
declarativo; (3) é constituída de várias subcompetências interconectadas; (4) o componente estratégico, como para todo conhecimento operacional, desempenha um papel determinante. Portanto, a CT não é essencialmente um conhecimento declarativo (um saber $o$ quê, fácil de verbalizar, que se adquire por meio de exposição e cujo processamento é essencialmente monitorado), mas, antes, um conhecimento operacional (ou procedimental): um saber como, difícil de verbalizar, adquirido através da prática e processado essencialmente de modo automático ${ }^{13}$.

No modelo que propomos, a CT é constituída de 5 subcompetências e componentes psicofisiológicos:

- Subcompetência bilíngue. Conhecimentos essencialmente operacionais, necessários para a comunicação em duas línguas. São conhecimentos pragmáticos, sociolinguísticos;

- Subcompetência extralinguística. Conhecimentos essencialmente declarativos, implícitos e explícitos, sobre o mundo em geral e em áreas específicas. São conhecimentos biculturais, enciclopédicos e temáticos, textuais e léxico-gramaticais;

- Subcompetência de conhecimentos sobre tradução. Conhecimentos essencialmente declarativos, implícitos e explícitos, sobre os princípios que regem a tradução e sobre os aspectos profissionais;

- Subcompetência instrumental. Conhecimentos essencialmente operacionais relativos à utilização das fontes de do-

13 Sobre as características do conhecimento declarativo e operacional (ou procedimental) cf. Anderson (1983), Pozo e Postigo (1993). Pozo e Postigo (49), baseando-se em Wellington (1989), propõem um terceiro tipo de conhecimento: o conhecimento explicativo, que está relacionado ao saber por que e que identifica os conhecimentos teóricos. Alguns autores (Paris; Lipson and Wixson, 1983; Paris, Cross and Lipson, 1984; Schraw and Moshman, 1995; etc.) também distinguem um conhecimento condicional, que consiste em saber quando e por que empregar os conhecimentos declarativos e operacionais. O conhecimento condicional tem uma grande importância para a didática.

Cad. Trad., Florianópolis, v. 40, n 1, p. 367-416, jan-abr, 2020. 
cumentação e às Tecnologias da Informação e Comunicação (TIC) aplicadas à tradução (dicionários de todo tipo, enciclopédias, gramáticas, suportes à redação, textos paralelos, corpora eletrônicos, mecanismos de pesquisa, etc.);

- Subcompetência estratégica. Conhecimentos operacionais permitindo a eficácia do processo de tradução e a resolução dos problemas encontrados. Trata-se de uma subcompetência chave que possui um impacto sobre todas as outras, relacionando-as, uma vez que ela monitora o processo de tradução. Essa subcompetência permite planejar o processo e elaborar o projeto de tradução (escolha do método exigido), avaliar o processo e os resultados parciais obtidos em função do objetivo final pretendido, ativar as diferentes subcompetências a fim de compensar certas lacunas, e identificar os problemas de tradução e aplicar os procedimentos para resolvê-los.

Existem, além disso, os componentes psicofisiológicos: componentes cognitivos e aspectos atitudinais de todos os tipos, e mecanismos psicomotores (memória, curiosidade intelectual, perseverança, rigor, espírito crítico, criatividade, raciocínio lógico, etc.). 
Figura 2: A competência tradutória de acordo com o modelo holístico do PACTE (2003)

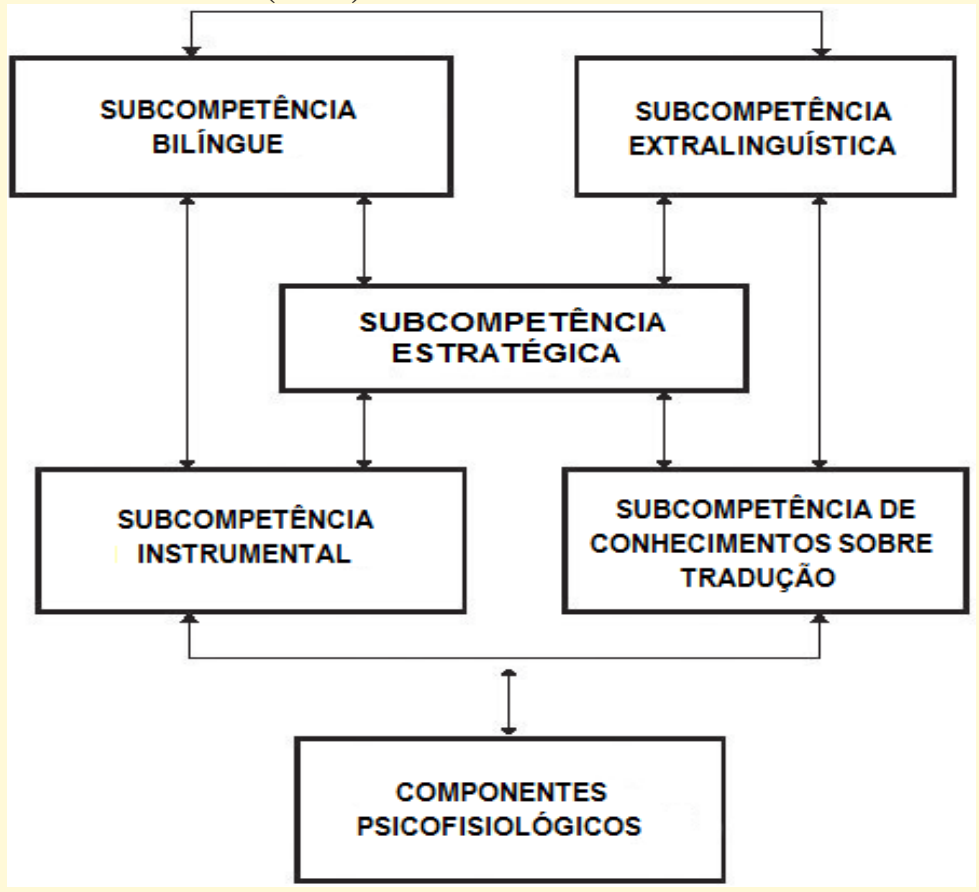

Fonte: PACTE (2003)

Todas essas subcompetências imbricam-se umas nas outras durante a tradução e existe entre elas uma certa hierarquia. É a subcompetência estratégica que desempenha um papel preponderante, na medida em que monitora o processo de tradução e serve para suprir as deficiências em relação às outras subcompetências.

\subsection{A aquisição da competência tradutória}

Para a aplicação didática, é preciso igualmente considerar o processo de aquisição da CT. O modo como se adquire a CT ainda não foi objeto de muitos estudos. Pode-se evocar as contribuições 
de Harris e Sherwood, Toury, Shreve e Chesterman. Harris ((a), (b), (c)), e Harris e Sherwood (1978) apontam a existência de uma habilidade inata de tradução, a tradução natural, que todo bilíngue possui e que seria uma das bases da CT. Toury (241-258) propõe um modelo do processo de conversão de um bilíngue em tradutor, por ele denominado socialização da tradução, e dentro do qual o feedback do entorno social desempenha um papel essencial. Shreve (1997) considera a CT como uma especialização da competência comunicativa, cujo desenvolvimento é um continuum entre a tradução natural e a tradução construída (a tradução profissional). Chesterman (1997), por sua vez, remete às cinco fases de Dreyfus e Dreyfus (1986): novice, advanced beginner, competence, proficiency e expertise ${ }^{14}$.

Embora existam alguns estudos empíricos que comparam o comportamento do tradutor profissional e o do estudante de tradução (cf., por exemplo, Jääskeläinen (a), (b); Tirkkonen-Condit, 1990; Jääskeläinen and Tirkkonen-Condit, 1991; Séguinot, 1991; Lorenzo, 1999), nenhum estudo empírico foi realizado sobre o processo de aquisição da CT como um todo. No modelo elaborado pelo grupo PACTE (2000), a aquisição da CT é um processo de reconstrução e desenvolvimento das subcompetências da CT e dos componentes psicofisiológicos. Sob esse ponto de vista, trata-se de um processo de reestruturação e desenvolvimento de um conhecimento novato (competência pré-tradutória) até um conhecimento especializado (CT). Como todo processo de aprendizagem, esse processo possui as seguintes características: (1) é dinâmico, cíclico e em espiral (não linear); (2) requer uma competência de aprendizagem (estratégias de aprendizagem); (3) comporta uma reestruturação e um desenvolvimento integrado de conhecimentos declarativos, operacionais e condicionais. Além dessas três características, no caso da aquisição da CT, o desenvolvimento do conhecimento

\footnotetext{
14 Dreyfus e Dreyfus identificam cinco estágios, mas sem lhes atribuir uma denominação exata; nós adotamos as denominações propostas por Chesterman para cada fase.
}

Cad. Trad., Florianópolis, v. 40, n⿳0 1, p. 367-416, jan-abr, 2020. 
operacional e, consequentemente, da competência estratégica, ocupa um lugar fundamental.

\section{Um desenho curricular por competências e tarefas de tradução na formação dos tradutores}

Do ponto de vista da formação de tradutores, a questão que se coloca é a seguinte: como operacionalizar essas propostas (formação por competências, e natureza da competência tradutória e sua aquisição) com o objetivo de elaborar um desenho curricular?

\subsection{Ponto de partida}

Nossa proposta de formação por competências na didática da tradução tem como ponto de partida nossa pesquisa anterior: a formação por objetivos de aprendizagem e tarefas de tradução.

Seguindo a linha traçada por Delisle ((a), (b)), que propunha objetivos de aprendizagem e utilizava uma metodologia ativa, aquela pesquisa anterior tinha por finalidade elaborar objetivos de aprendizagem, bem como um quadro metodológico. Nesse sentido, propusemos quatro categorias de objetivos de aprendizagem da didática da tradução: objetivos metodológicos, contrastivos, profissionais-instrumentais e textuais (Hurtado Albir, (c), (d)).

Nossa proposta de um enfoque por tarefas e projetos de tradução não constitui apenas um quadro metodológico, mas um quadro para o desenho curricular, pois ela possibilita uma integração de todos os elementos do processo educativo: objetivos, conteúdos, metodologia e avaliação ${ }^{15}$.

15 Essa proposta, que data do início dos anos 1990 (Hurtado Albir, (a), (b)), foi desenvolvida sobretudo de 1995 a 1997, por ocasião de um projeto de pesquisa da Universidade Jaume I de Castellon (Espanha), que coordenamos; a finalidade desse projeto era propor os objetivos de aprendizagem e a metodologia específicos para as disciplinas de língua, tradução e interpretação no âmbito da graduação em tradução. Essa proposta levou em consideração os principais perfis profissionais 


\subsection{Arcabouço teórico}

Todo arcabouço teórico para a elaboração de uma didática é duplo: um arcabouço teórico da disciplina em questão (no nosso caso, um arcabouço tradutológico) e um arcabouço teórico de tipo pedagógico.

No que diz respeito ao arcabouço tradutológico, é necessário, a nosso ver, levar em consideração as quatro questões seguintes:

1. Qual concepção da tradução? Inicialmente, qual é a concepção da prática que queremos ensinar (em nosso caso, a tradução)? Nesse sentido, propusemos uma concepção integralizadora da tradução, considerando-a como uma atividade textual, comunicativa e cognitiva. Tal concepção demanda, por sua vez, uma concepção integralizadora da Tradutologia (a disciplina que estuda essa prática), que associe fundamentalmente as contribuições das abordagens textuais, comunicativo-socioculturais e cognitivas (cf. Hurtado Albir, (e)).

2. Qual concepção da competência tradutória? Em seguida, quais são as competências necessárias para traduzir? O modelo holístico da CT do grupo PACTE considera a CT como um conhecimento especializado, essencialmente operacional e qualitativamente diferente da competência bilíngue, compreendendo diferentes subcompetências interconectadas.

3. Quais tarefas o tradutor é levado a realizar no seu contexto profissional? É necessário igualmente considerar as práticas (dominantes e emergentes) correspondentes à demanda no mercado de trabalho ${ }^{16}$. Esse aspecto complementa o ante-

do ofício de tradutor: tradução jurídica, técnica, audiovisual e literária. Os primeiros resultados dessa pesquisa foram tema de um livro, Enseñar a traducir (Ensinar a traduzir) (Hurtado Albir, (d)), e continuam sendo publicados na coleção Aprender a traducir (Aprender a traduzir), criada em 2004, e que propõe manuais destinados aos estudantes (cf. Brehm; Gamero; Borja).

${ }^{16}$ Atualmente, dispomos de diferentes pesquisas sobre o mercado da tradução

Cad. Trad., Florianópolis, v. 40, ${ }^{0}{ }^{1}$, p. 367-416, jan-abr, 2020. 
rior: trata-se de reunir os dados do funcionamento cognitivo da CT (o que é preciso para ser tradutor) e do funcionamento comportamental (o que o tradutor faz); os dois, em conjunto, ajudam-nos a traçar o perfil profissional do tradutor.

4. Como se adquire a competência tradutória? Por fim, é necessário levar em consideração a aquisição da competência tradutória. No modelo do grupo PACTE, essa aquisição é compreendida como um processo dinâmico e em espiral, que começa por uma competência pré-tradutória (conhecimento novato) e termina por uma CT (conhecimento especializado).

No que tange ao arcabouço pedagógico, duas questões essenciais intervêm:

1. Qual concepção da aprendizagem? As diferentes teorias construtivistas da aprendizagem (cognitivas e sociais), que surgiram com os trabalhos de Piaget (1947) e Vygotsky $(1934,1984)$, oferecem o suporte teórico necessário ${ }^{17}$. Lembremos que um dos pressupostos essenciais do construtivismo é que os indivíduos participam ativamente do seu aprendizado e que cabe a eles construir seus conhecimentos, conhecimentos esses que são adquiridos gradualmente e em contexto, por meio da experiência e do diálogo com os conhecimentos anteriores.

2. Qual concepção do ensino? O processo educativo é, no entanto, muito complexo e requer uma interação entre ensino e aprendizagem. As teorias da aprendizagem são insuficientes por si sós para organizar o ensino, pois é necessário um quadro explicativo que permita seu planejamento; esse quadro é dado pelas diferentes pesquisas que foram feitas sobre

realizadas em diferentes países. Cf. a esse respeito Kuznik (139-166), que analisa dez pesquisas: Golden, Hurtado e Piqué (1992), Hermans e Lambert (1998), Mackenzie (2000), Li (2000), Ørsted (2001), Calvo Encinas (2004).

${ }^{17}$ Em relação ao construtivismo em Tradutologia, cf. Kiraly (b). 
o ensino. O eixo fundamental que faz a ligação entre todas essas pesquisas é o desenho curricular. Diferentemente de uma abordagem mais tradicional, centrada unicamente nos conteúdos, preconiza-se atualmente uma abordagem aberta e integralizadora do desenho curricular, que considere também com qual objetivo se ensina, como, quando e com qual resultado $^{18}$. O objetivo dessa abordagem é implicar professores e estudantes na tomada de decisões, bem como integrar os diferentes eixos do processo educativo (objetivos, conteúdos, metodologia e avaliação) planejando os objetivos e os conteúdos, e levando em conta as decisões sobre a metodologia e a avaliação. São esses os princípios que norteiam a FPC.

A formação por competências e tarefas de tradução que propomos resulta do duplo arcabouço teórico que acaba de ser exposto.

\subsection{Competências específicas na formação de tradutores: categorias de competências}

Nossa proposta de competências específicas para a didática da tradução toma como ponto de partida nossa proposta de objetivos de aprendizagem (Hurtado Albir (c), (d)).

Esta proposta de categorias de competências específicas de tradução diz respeito às disciplinas diretamente implicadas na formação de tradutores, isto é: Introdução à Tradução para a língua materna (a "tradução geral"), a tradução para a língua estrangeira, bem como os diferentes ramos de especialização (tradução técnica, tradução científica, tradução jurídica, tradução audiovisual, tradução literária, localização, etc. $)^{19}$.

${ }^{18} \mathrm{Cf}$. a esse respeito a excelente apresentação que Kelly (b) faz sobre as bases do desenho curricular e sua aplicação em Tradutologia.

19 Além dessas disciplinas que poderíamos considerar centrais na formação dos tradutores, outras disciplinas "auxiliares" intervêm de acordo com as características e o nível de formação: ensino de línguas para tradutores (materna e estrangeiras), tecnologias da informação e da comunicação, documentação, terminologia, etc.

Cad. Trad., Florianópolis, v. 40, n⿳ 1, p. 367-416, jan-abr, 2020. 
Propomos seis categorias de competências específicas: metodológicas e estratégicas, contrastivas, extralinguísticas, profissionais, instrumentais e textuais. O quadro a seguir resume o conteúdo dessas categorias de competências.

Figura 3: Categorias de competências específicas na formação de tradutores

\section{COMPETÊNCIAS METODOLÓGICAS E ESTRATÉGICAS}

- Competências relacionadas aos princípios e às estratégias que devem ser aplicados para se percorrer corretamente o processo de tradução e se poder chegar à solução de tradução que convém conforme o caso. Servem para apreender princípios e desenvolver habilidades ligadas à prática da tradução.

- Elas desenvolvem a subcompetência estratégica, os conhecimentos sobre tradução e certos componentes psicofisiológicos da CT.

- ENUNCIADO: Aplicar os princípios metodológicos e as estratégias necessárias para se percorrer corretamente o processo de tradução.

\section{COMPETÊNCIAS CONTRASTIVAS}

- Competências relacionadas ao conhecimento das diferenças entre as duas línguas e ao monitoramento de interferências.

- Elas desenvolvem a subcompetência bilíngue da CT.

- Elas são importantes para a Introdução à Tradução (para a língua materna e para a língua estrangeira).

- ENUNCIADO: Diferenciar as duas línguas e monitorar as interferências.

\section{COMPETÊNCIAS EXTRALINGUÍSTICAS}

- Competências relacionadas à mobilização de conhecimentos enciclopédicos, biculturais e temáticos.

- Elas desenvolvem a subcompetência extralinguística da CT.

- Elas são importantes em tradução especializada (conhecimentos temáticos de áreas específicas).

- ENUNCIADO: Mobilizar conhecimentos enciclopédicos, biculturais e temáticos para resolver problemas de tradução.

\section{COMPETÊNCIAS PROFISSIONAIS}

- Competências relacionadas ao conhecimento do mercado de trabalho.

- Elas desenvolvem a subcompetência de conhecimentos da tradução (no tocante aos aspectos profissionais).

- ENUNCIADO: Agir com eficácia no mundo do trabalho. 


\section{COMPETÊNCIAS INSTRUMENTAIS}

- Competências relacionadas à utilização de fontes de documentação e de ferramentas de todo tipo, úteis ao tradutor (em suporte informático, papel, etc.).

- Elas desenvolvem a subcompetência instrumental da CT.

- ENUNCIADO: Gerenciar a documentação e ferramentas de todo tipo para resolver problemas de tradução.

\section{COMPETÊNCIAS TEXTUAIS}

- Competências relacionadas à resolução dos diferentes problemas de tradução que surgem de acordo com os diferentes funcionamentos textuais.

- Elas desenvolvem de forma integrada todas as subcompetências da CT e os componentes psicofisiológicos.

- ENUNCIADO: Resolver problemas de tradução de diferentes gêneros textuais utilizando as estratégias apropriadas.

Fonte: (Hurtado Albir, 2007)

A partir dessas categorias de competências, é possível expor as que são próprias a cada disciplina. Vejamos o exemplo das competências específicas da Introdução à Tradução para a língua materna (Hurtado Albir, (f)):

1. Aplicar os princípios metodológicos e as estratégias elementares para percorrer corretamente o processo de tradução;

2. Diferenciar as duas línguas e monitorar as interferências;

3. Mobilizar conhecimentos enciclopédicos, biculturais e temáticos para resolver problemas elementares de tradução;

4. Gerenciar as questões elementares para agir no mercado de trabalho;

5. Gerenciar a documentação e as ferramentas elementares para resolver problemas de tradução de textos não especializados;

6. Resolver problemas de tradução de textos não especializados utilizando as estratégias apropriadas. 


\subsection{Operacionalização das competências}

As competências tomam forma somente quando o processo de operacionalização é instaurado, isto é, quando elas são definidas de um modo que permita efetuar o planejamento didático.

Existem diferentes modelos de operacionalização, pois os critérios podem ser modificados conforme as instituições. Lasnier (46), por exemplo, propõe definir o enunciado da competência, os componentes da competência, as manifestações (os elementos observáveis), o sentido e o alcance da competência, o contexto de realização, o conteúdo disciplinar, os critérios de avaliação e as relações entre as competências.

Quanto a nós, pensamos que convém definir, pelo menos, quatro desses aspectos:

- O enunciado da competência. Esse enunciado, de acordo com Lasnier $(47 ; 62)$, oferece uma ideia geral da competência. É necessário formulá-lo com a ajuda de um verbo de ação observável e no infinitivo ${ }^{20}$, e um ou mais complementos que contextualizem a competência;

- Os componentes da competência, isto é, os elementos que fazem parte da competência. Esses elementos, segundo Lasnier $(47 ; 63)$, fazem parte do processo geralmente aplicado quando se implementa a competência, e eles identificam as grandes etapas que conduzirão ao domínio da competência. Ademais, eles são enunciados por meio de um verbo no infinitivo e um ou mais complementos, tais complementos devendo indicar o conteúdo disciplinar associado. A definição dos componentes da competência é uma base para os descritores de avaliação;

- O conteúdo disciplinar associado. Os conteúdos não são um elemento à parte; a apropriação dos conteúdos deve ser feita

${ }^{20}$ Lembremos, a esse propósito, que existem diferentes taxonomias que ajudam a definir as aprendizagens: a de Bloom (1956), a da esfera afetiva de Metfessel, Michael e Kirsner (1969), a de Biggs (2005) por níveis de complexidade, etc.

Cad. Trad., Florianópolis, v. 40, ${ }^{0}{ }^{1}$, p. 367-416, jan-abr, 2020. 
a partir das competências, da mobilização dos elementos que a compõem. Desse modo, a apropriação se faz em contexto;

- Os descritores da competência, isto é, os elementos observáveis que servem de base para a avaliação e para os quais é preciso definir diferentes níveis de conhecimento.

Por outro lado, é evidente que convém definir as atividades que permitem alcançar a competência. Trata-se aqui das tarefas que o estudante realizará para conseguir dominar a competência; no nosso caso, as tarefas relacionadas à tradução.

Eis um exemplo de operacionalização de uma competência da Introdução à Tradução ${ }^{21}$ : a competência metodológica e estratégica.

Figura 4: Operacionalização da competência metodológica e estratégica da Introdução à Tradução

\begin{tabular}{|l|}
\hline \multicolumn{1}{|c|}{ COMPETÊNCIA METODOLÓGICA E ESTRATÉGICA } \\
\hline ENUNCIADO: Aplicar os princípios metodológicos e as estratégias elementares para percorrer \\
corretamente o processo de tradução. \\
COMPONENTES \\
1. Identificar a tradução como um ato de comunicação direcionado a um destinatário. \\
2. Compreender textos não especializados da língua de partida utilizando as estratégias \\
apropriadas. \\
3. Produzir em língua de chegada textos não especializados claros e sem decalques, utilizando \\
estratégias apropriadas. \\
4. Encontrar a equivalência de tradução utilizando as técnicas e as estratégias apropriadas. \\
5. Identificar e resolver problemas de tradução elementares utilizando as estratégias \\
apropriadas. \\
6. Identificar e corrigir os erros de tradução elementares justificando as soluções. \\
7. Percorrer as diferentes etapas de elaboração de uma tradução realizando as tarefas \\
apropriadas e utilizando as estratégias apropriadas.
\end{tabular}

${ }^{21}$ Sobre os componentes e o conteúdo disciplinar de todas as competências da Introdução à Tradução, cf. Hurtado Albir (2007).

Cad. Trad., Florianópolis, v. 40, nº 1, p. 367-416, jan-abr, 2020. 


\section{CONTEÚDO DISCIPLINAR}

\section{A finalidade comunicativa da tradução}

- A tradução como processo de compreensão e de reexpressão.

- A importância da finalidade e do destinatário da tradução.

- Estratégias elementares para captar a informação de um texto e reformulá-lo claramente em outra língua: colocar-se dentro da situação (imaginar o contexto do original), concentrar-se mais nas ideias do que na forma, visualizar os fatos expostos pelo texto, assumir o papel de emissor real na língua de chegada, procurar a espontaneidade na língua de chegada, pensar no destinatário, etc.

\section{A importância da fase de compreensão}

- A necessidade de compreender para traduzir.

- A compreensão como processo interpretativo de apreensão do sentido dos textos.

- Estratégias elementares para apreender 0 sentido: identificar 0 contexto de surgimento do original; identificar a função prioritária do texto; destacar as ideias principais e secundárias; questionar-se sobre a progressão e 0 encadeamento da informação; identificar os principais traços estilísticos; identificar as referências culturais; aplicar o raciocínio lógico; integrar os conhecimentos extralinguísticos, etc.

\section{A importância da língua de chegada}

- A importância de ser um excelente redator na língua materna, atentando para a clareza e a correção da língua.

- Os problemas de interferência e decalque linguístico; os problemas decorrentes da literalidade no caso de línguas próximas. A necessidade de separar as duas línguas.

- Estratégias elementares para reformular corretamente 0 sentido do texto original: não colar à língua de partida, procurar meios específicos da língua de chegada, desconfiar das palavras e estruturas que não são naturais na língua de chegada, evitar o uso de palavras excessivamente parecidas com aquelas do texto original para evitar os falsos amigos, etc.

\section{0 dinamismo da equivalência de tradução e seu caráter textual}

- 0 dinamismo da equivalência de tradução. 0 caráter textual e contextual da equivalência de tradução.

- A importância da organização textual e da imbricação das unidades de tradução para a pesquisa de equivalências; a interpretação dos elementos de coerência e coesão.

- A pesquisa de equivalências como processo analógico e de exploração profunda da língua de chegada.

- 0 uso de técnicas de tradução diferentes conforme 0 caso: adaptação, amplificação/redução, decalque, compensação, criação discursiva. empréstimo, generalizaçãp/particularização, modulação, tradução literal, transposição, etc. 
- Estratégias elementares para encontrar equivalências: seguir mais a lógica do texto do que as palavras e as frases, repetir várias vezes e de diferentes maneiras (paráfrase) a mesma unidade em língua de chegada, efetuar pesquisas em dicionários analógicos, etc.

\section{A identificação e a resolução de problemas elementares de tradução}

- A identificação de problemas de tradução. Problemas de compreensão e problemas de reformulação. Tipos de problemas de tradução: linguísticos, textuais, extralinguísticos e pragmáticos.

- 0 processo de resolução de problemas de tradução. Fases: identificação do problema, definição do tipo de problema, seleção e aplicação de estratégias, avaliação da solução.

- Estratégias elementares de resolução de problemas de tradução com vistas ao planejamento, leitura, redação, documentação, revisão e correção.

\section{A identificação e a correção de erros elementares de tradução}

- A identificação de erros de tradução. Tipos de erros de tradução: inadequações que afetam a compreensão do texto original; inadequações que afetam a reexpressão em língua de chegada; inadequações pragmáticas.

- As causas do erro de tradução: sua relação com insuficiências em uma ou mais subcompetências.

- A correção de erros de tradução.

\section{As etapas da elaboração de uma tradução}

- A fase de orientação (antes). Situar o texto e fazer uma leitura exaustiva; identificar as carências linguísticas e extralinguísticas; detectar os problemas de compreensão e de reformulação; planejar as tarefas de documentação; etc.

- A fase de desenvolvimento (durante). Aplicar os princípios e as estratégias para apreender e reformular o sentido.

- A fase de revisão (depois). Revisar e avaliar a tradução, verificando: a clareza das ideias; a correção ortográfica, lexical, morfossintática e estilística; a exatidão dos números, dos dados, dos nomes próprios e das enumerações, a adequação dos aspectos formais, etc.

0 estudante:

\section{DESCRITORES}

1. Produz traduções comunicativas.

2. Apreende o sentido de textos não especializados em língua de partida e utiliza estratégias de leitura apropriadas.

3. Produz em língua de chegada textos não especializados claros e sem decalques e utiliza estratégias de escrita apropriadas. 
4. Propõe soluções de tradução dinâmicas conforme o contexto e utiliza técnicas e estratégias apropriadas.

5. Identifica e resolve problemas de tradução elementares e utiliza estratégias apropriadas.

6. Identifica e corrige erros elementares de tradução e justifica soluções corretas.

7. Percorre as diferentes etapas da elaboração de uma tradução, realiza as tarefas apropriadas e utiliza estratégias apropriadas.

Fonte: elaborada pela autora

Para cada descritor, é preciso especificar os critérios para os diferentes níveis de conhecimento. Alguns modelos definem cinco níveis, outros quatro, três, dois, etc. Eis um exemplo para um descritor da competência metodológica e estratégica da Introdução à Tradução, com definição de três níveis de conhecimento:

Figura 5: Níveis de conhecimento para um descritor da competência metodológica e estratégica da Introdução à Tradução

\begin{tabular}{l} 
Descritor 3: 0 estudante produz em língua de chegada textos não especializados claros e sem \\
decalques e utiliza estratégias de escrita apropriadas. \\
\hline BOM NÍVEL \\
0 estudante transmite as ideias claramente, estrutura-as corretamente no texto, formula- \\
as corretamente (variedade na estruturação das frases, vocabulário adequado e variado) \\
e respeita as exigências da língua de chegada (conectores, elementos referenciais, \\
morfossintaxe, vocabulário, ortografia, pontuação). \\
NÍVEL MÉDIO \\
O estudante transmite a maior parte das ideias claramente e desrespeita certas exigências da \\
língua de chegada (conectores, elementos referenciais, morfossintaxe, vocabulário, ortografia, \\
pontuação). \\
NÍVEL INSUFICIENTE \\
0 estudante transmite apenas algumas ideias claramente e desrespeita muitas exigências da \\
língua de chegada (conectores, elementos referenciais, morfossintaxe, vocabulário, ortografia, \\
pontuação).
\end{tabular}

Fonte: elaborada pela autora 


\subsection{Sequenciamento das unidades didáticas}

Outro aspecto do desenho curricular é o sequenciamento ou a divisão em unidades didáticas. Vejamos a definição de sequência de aprendizagem proposta por Lasnier: "Um agrupamento coerente de tarefas integralizadoras e de atividades de aprendizagem visando à integração de um conjunto de competências e à apropriação de conteúdo disciplinar possuindo características semelhantes" (Lasnier 211). Existem, portanto, dois aspectos fundamentais que devem ser levados em conta para a divisão das unidades didáticas. Por um lado, a existência de um conteúdo disciplinar semelhante e, por outro, a realização de atividades de aprendizagem e de tarefas integralizadoras que visem à integração de competências.

É nesse espírito que propomos o seguinte sequenciamento de unidades didáticas para a Introdução à Tradução (francês-espanhol):

1. A finalidade comunicativa da tradução;

2. A importância da língua de chegada ${ }^{22}$;

3. A importância da fase de compreensão;

4. O dinamismo da equivalência de tradução;

5. O espírito crítico. Levantamento dos problemas e erros de tradução;

6. As diferenças linguísticas entre o francês e o espanhol;

7. As diferenças textuais entre o francês e o espanhol;

8. Os conhecimentos extralinguísticos. Os referentes culturais;

9. As ferramentas do tradutor. As fontes de documentação;

10. O mercado de trabalho;

11. A tradução de textos de diferentes tipos;

12. A tradução de textos de diferentes registros.

22 Consideramos que essa unidade deve se situar no início da aprendizagem, pois a sensibilização sobre a importância da língua de chegada faz com que o estudante descubra imediatamente a função comunicativa da tradução, bem como a necessidade de qualidade do produto final.

Cad. Trad., Florianópolis, v. 40, n⿳ 1, p. 367-416, jan-abr, 2020. 


\subsection{Elaboração da unidade didática. $O$ enfoque por tarefas de tradução}

Chegamos agora a outro aspecto do desenho curricular: a elaboração da unidade didática. Já dissemos que as competências mobilizam conhecimentos, habilidades e atitudes que são aplicados com vistas à realização de uma dada tarefa em um contexto. Sob esse aspecto, consideramos que o enfoque por tarefas e projetos de tradução oferece um quadro pertinente para a elaboração da unidade didática que possibilita ao estudante adquirir as competências para traduzir.

\section{a. O enfoque por tarefas de tradução}

Considerando que os fundamentos do enfoque por tarefas e projetos, utilizado em didática das línguas e em outras disciplinas ${ }^{23}$, são de grande interesse para a didática da tradução, propusemos um enfoque por tarefas e projetos de tradução (Hurtado Albir, (a), (b), (c), (d) $)^{24}$. Nessa abordagem, a unidade didática é uma sequência de tarefas em que se confere uma grande importância às tarefas preparatórias, isto é, às tarefas de aprendizagem que ajudam a apreender princípios ou estratégias e que preparam para a tarefa final (por exemplo, traduzir um testamento, um contrato, etc.). No entanto, não é preciso, sobretudo no início da aprendizagem, incorporar necessariamente uma tarefa final.

Lembremos que o enfoque por tarefas não é apenas um arcabouço metodológico, mas também um arcabouço para o desenho curricular. Trata-se, ademais, de um quadro curricular integrativo, já que integra todos os elementos do processo educativo (objetivos, conteúdos, metodologia e avaliação); o desenho curricular é concebido de maneira integrada, imbricando resultados e processos, objetivos e meios, e redefinindo os papéis do professor e do

${ }^{23}$ Cf. as contribuições de Candlin e Murphy (1987), Nunan (1989), Hutchinson (1991), Ribe e Vidal (1993), Estaire e Zanón (1994), Willis (1996), etc.

${ }^{24}$ Em Gonzáles Davies ((a), (b)), o enfoque por tarefas é igualmente utilizado para a didática da tradução.

Cad. Trad., Florianópolis, v. 40, n 1, p. 367-416, jan-abr, 2020. 
estudante. A tarefa torna-se a coluna vertebral para a elaboração da unidade didática e o desenho curricular. A unidade didática é configurada como um conjunto de tarefas cuja finalidade é atingir os objetivos estabelecidos. A programação das unidades é, desse modo, um processo de sequenciamento de tarefas.

Retomando as características da tarefa segundo Zanón (1990), definimos a tarefa de tradução como uma unidade de atividades, representativa da prática da tradução, que se destina à aprendizagem da tradução e que possui um objetivo concreto, uma estrutura e uma sequência de trabalho (Hurtado Albir (b) 56). Em Enseñar a traducir (Hurtado Albir, (d)), diferentes exemplos de elaboração da unidade didática foram propostos segundo o enfoque por tarefas. Cada unidade é estruturada em diferentes tarefas (de aprendizagem, de tradução) que preparam para a/s tarefa/s final/ais à/s qual/quais são integrados os conhecimentos adquiridos graças às tarefas preparatórias. Para cada tarefa, estabelecem-se os objetivos pretendidos, o material empregado (textos a traduzir, textos paralelos, traduções, fichas, baremas, etc.), o andamento da tarefa (atividades, fases, dinâmica de grupos, etc.), a avaliação, assim como comentários suplementares (possíveis modificações, pós-tarefas, etc.). Essas tarefas podem ser feitas dentro ou fora da sala de aula; podem ser dirigidas ou autônomas, individuais ou em grupo.

Pode-se igualmente considerar a elaboração de projetos de tradução: nesse caso, visa-se a uma tarefa aberta e global, de grande envergadura (a tradução de um filme, de uma monografia científica ou técnica, da documentação de um processo de divórcio, da criação de uma empresa, etc.), que demanda um grande sequenciamento de tarefas.

\section{b. Tarefas de aprendizagem, tarefas de integração, tarefas integralizadoras}

Já dissemos que um conceito-chave da FPC é a integração; uma das principais estratégias dessa integração é o que Lasnier chama "a tarefa integralizadora": 
uma situação de aprendizagem contextualizada e complexa que leva os estudantes a ativarem uma ou várias competências disciplinares, levando em conta, ao mesmo tempo, pelo menos uma competência transversal e uma esfera de experiência de vida, e que favorece seu desenvolvimento e sua habilidade na ação (Lasnier 196).

Como indicamos reiteradas vezes, nem todas as tarefas possuem o mesmo status. Lasnier $(148 ; 196)$ estabelece a esse propósito a distinção entre atividades de aprendizagem, tarefas de integração e tarefas integralizadoras.

1. As atividades de aprendizagem são centradas no desenvolvimento de uma capacidade ou um conteúdo disciplinar;

2. As tarefas de integração são aquelas que ativam todos os componentes de uma competência;

3. As tarefas integralizadoras ativam uma ou várias competências disciplinares e, pelo menos, uma competência geral e uma esfera de experiência da vida contemporânea ${ }^{25}$. A tarefa integralizadora ativa os componentes de uma competência, mas, além disso, ela os integra porque mobiliza os conhecimentos (declarativos, operacionais e condicionais) que a ela estão relacionados.

O enfoque por tarefas é, a nosso ver, um instrumento que permite alcançar uma integração das tarefas de aprendizagem, das tarefas de integração e das tarefas integralizadoras. Nesse sentido, consideramos que as tarefas finais são formadas por tarefas de integração, que ativam os componentes de uma competência (ou pelo menos um desses componentes), ou por tarefas integralizadoras de tradução, que ativam no mínimo uma competência específica e uma competência geral.

25 As "esferas de experiência de vida" são os aspectos da vida contemporânea que o estudante é convidado a explorar regularmente: saúde e bem-estar, meio ambiente, mídia, etc. (Lasnier 43).

Cad. Trad., Florianópolis, v. 40, ${ }^{0}{ }^{1}$, p. 367-416, jan-abr, 2020. 
É evidente que nem todas as tarefas podem ser integralizadoras, sobretudo no início de uma aprendizagem, uma vez que são necessárias tarefas de aprendizagem e de integração que preparem para a realização de tarefas integralizadoras de tradução. É o princípio de alternância da FPC. Em nossa proposta de categorias de competências, as tarefas integralizadoras dizem respeito sobretudo às competências textuais (em cada ramo do ensino da tradução).

\section{c. Exemplo de unidade didática de Introdução à Tradução}

Eis um exemplo de unidade didática para a Introdução à Tradução, relativo a um dos componentes da competência metodológica e estratégica: "A importância da língua de chegada" ${ }^{26}$.

Figura 6: Unidade didática para a Introdução à Tradução relativa ao componente da competência metodológica e estratégica "A importância da língua de chegada"

\section{UNIDADE: A IMPORTÂNCIA DA LÍNGUA DE CHEGADA (LC)}

COMPETEENCIAS ESPECIF́FICAS: Metodológica e estratégica. Componente: produzir em LC textos não especializados claros e sem decalques, utilizando as estratégias apropriadas.

COMPETÊNCIAS GERAIS: Análise e síntese, tomada de decisões, trabalho em equipe e preocupação com a qualidade.

TAREFA 1. Destacar erros linguísticos (dirigida, em grupo).

TAREFA 2. Identificar decalques e elaborar um catálogo (dirigida, em grupo).

TAREFA 3. Detectar boas soluções de tradução (dirigida, individual/em grupo).

TAREFA 4. Propor soluções idiomáticas (autônoma, em grupo).

TAREFA 5. Elaborar um resumo (autônoma, individual).

Fonte: elaborada pela autora

${ }^{26}$ Essa unidade foi pensada para a tradução entre línguas próximas, na qual a influência exercida pela língua de partida é constantemente um obstáculo para a correção da tradução.

Cad. Trad., Florianópolis, v. 40, ${ }^{0}{ }^{1}$, p. 367-416, jan-abr, 2020. 
São tarefas de aprendizagem, já que se trata da Introdução à Tradução. Diferentes tipos de tarefas, a serem realizadas na - ou fora da - sala de aula, compõem a unidade didática: tarefas dirigidas ou autônomas, em grupo ou individuais. O objetivo é conduzir o estudante a atividades autônomas e individuais ao final da unidade. Vejamos uma breve explicação das tarefas que compõem a unidade:

1. Destacar os erros linguísticos. Sem conhecer o/s texto/s origina/l/is, identificação de erros em uma ou várias traduções excessivamente calcadas na língua de partida e carentes de idiomaticidade: erros de pontuação, ortografia, léxico, morfossintaxe, conectores, elementos de referência, coerência, estilo inapropriado, etc. Pode-se recorrer a uma ficha com as categorias ou tentar identificá-las em conjunto;

2. Identificar decalques e elaborar um catálogo. Comparação com $\mathrm{o} / \mathrm{s}$ texto/s origina/l/is e identificação da origem dos erros. Elaboração de um catálogo de decalques com os erros encontrados, classificando-os de acordo com as diferentes categorias. Esse catálogo se ampliará ao longo do curso;

3. Detectar boas soluções de tradução. Comparação de duas traduções de um mesmo texto original, uma literal e outra idiomática, para detectar as inadequações e as boas soluções de cada uma. É uma oportunidade para começar a ampliar o catálogo dos decalques e começar a acrescentar soluções idiomáticas nele;

4. Propor soluções idiomáticas. Identificação de erros linguísticos em uma tradução e proposição de soluções idiomáticas e claras;

5. Elaborar um resumo. Elaboração de um resumo dessa tradução (50\% do texto original), identificando as ideias-chave e atentando para a clareza e a idiomaticidade da expressão.

No que diz respeito à avaliação da unidade, pode-se prever uma avaliação entre os grupos (para as tarefas em grupo) e incorporar uma autoavaliação individual final, para que o estudante se questio- 
ne sobre sua capacidade de produzir textos claros e idiomáticos em língua de chegada, e identifique seus pontos fortes e fracos.

\section{d. A integração de competências. Vantagens do enfoque por tarefas de tradução}

Essa forma de conceber a elaboração da unidade didática permite a integração de competências específicas e gerais. Seja, por exemplo, a unidade didática proposta acima para a Introdução à Tradução, em que, além do trabalho sobre um componente de uma competência específica ("Produzir em língua de chegada textos não especializados claros e sem decalques utilizando estratégias apropriadas"), foram integradas competências gerais, tais como a análise e a síntese, a tomada de decisões, o trabalho em equipe e a preocupação com a qualidade. É, portanto, à elaboração da unidade didática e, em suma, às tarefas, que as competências gerais são integradas.

$\mathrm{O}$ enfoque por tarefas de tradução possibilita essa integração. Ademais, ele oferece, a nosso ver, as seguintes vantagens:

- permite que se criem situações relacionadas à vida profissional (tarefas autênticas);

- fornece uma metodologia ativa;

- obtém-se uma pedagogia que visa a percorrer processos;

- o estudante, além de assimilar princípios, aprende a resolver problemas e adquire as estratégias para fazê-lo;

- implanta-se uma pedagogia centrada no estudante, que realiza constantemente tarefas;

- obtém-se um quadro flexível de desenho curricular aberto a modificações, uma vez que esse desenho possibilita a introdução constante de tarefas de avaliação formativa.

O enfoque por tarefas permite, ainda, que sejam integrados, à planificação das tarefas, elementos de certas metodologias ativas, tais como a aprendizagem por problemas, o estudo de caso, o ensino estratégico, a aprendizagem cooperativa, etc. 


\subsection{A avaliação}

Chegamos enfim ao último aspecto do desenho curricular: a avaliação, compreendida como a obtenção de informação sobre o processo de aprendizagem com o objetivo de tomar decisões. Lembremos que essas decisões podem ser de diversos tipos: qualificar (a avaliação somativa), verificar o processo de aprendizagem (a avaliação formativa) ou identificar as características dos estudantes (a avaliação diagnóstica).

\section{a. Princípios}

Face à dificuldade de avaliar não apenas conhecimentos, mas habilidades e atitudes, os principais desafios da avaliação na didática da tradução são, em nossa opinião:

1. Conceder uma grande importância à avaliação formativa. Consideramos que ela é muito importante, já que produz retroação: (a) para o professor, que pode modificar sua prática a partir dos resultados da avaliação; (b) para o estudante, que pode fazer um diagnóstico de seu grau de competência e melhorá-lo caso necessário, desempenhando dessa forma um papel ativo em sua aprendizagem. Bonsón e Benito (90) falam, nesse sentido, de uma avaliação para a aprendizagem;

2. Avaliar o produto e o processo, as habilidades e as atitudes. É preciso em seguida estabelecer procedimentos e instrumentos para avaliar não apenas o produto da tradução (a tradução proposta), mas o processo contínuo que levou a esse resultado, assim como as habilidades e as atitudes do estudante relativas à tarefa de tradução;

3. Promover a autoavaliação do estudante. A autoavaliação feita pelo estudante suscita uma reflexão sobre sua aprendizagem, uma vez que facilita a capacidade de reconhecer quais elementos ajudam e quais elementos dificultam a aprendizagem; é a consciência mesma da aprendizagem. Lembremos que a reflexão sobre a própria prática é muito importante na 
vida profissional futura; isso tem relação com a aprendizagem contínua, que é essencial em tradução, cujo mercado profissional muda constantemente. A autoavaliação é, definitivamente, um ponto de partida para se progredir na vida profissional;

4. Estabelecer um continuum entre aprendizagem e avaliação, utilizando tarefas similares para a aprendizagem, a avaliação formativa e a avaliação somativa;

5. Desenvolver uma avaliação com critérios. É preciso também desenvolver critérios de avaliação; nesse sentido, a importância dos descritores, os comportamentos observáveis (cf. supra 4.4), que devem decorrer necessariamente dos componentes de cada competência;

6. Desenvolver uma avaliação autêntica. Fazer uma avaliação autêntica, com atividades reais, comparáveis àquelas que são realizadas na vida profissional;

7. Utilizar uma avaliação dinâmica que vise à triangulação. Trata-se enfim de utilizar uma avaliação dinâmica, mobilizando diferentes estratégias de avaliação segundo o nível e a situação de aprendizagem, e avaliando um mesmo descritor em diferentes momentos da aprendizagem. Isso permite fazer a "triangulação" (para empregar um termo da pesquisa empírica) 27 do estudante, ou seja, coletar informação a partir de ângulos diversos: diferentes conhecimentos, habilidades e atitudes.

\section{b. Planejamento}

Todo planejamento da avaliação implica três tipos de pergunta:

1. O que se avalia? Quer dizer, quais descritores de domínio da competência e qual nível (cf. supra 4.4);

2. Quando se avalia? Ou seja, em que momento do processo

${ }^{27}$ Fala-se de "triangulação" na pesquisa empírica quando, para se analisar um fenômeno, utilizam-se pelo menos três pontos de vista.

Cad. Trad., Florianópolis, v. 40, n 1, p. 367-416, jan-abr, 2020. 
de aprendizagem. Yániz e Villardón (82) distinguem a esse propósito três tipos de avaliação, cada uma com finalidades diferentes, as duas primeiras sendo mais formativas e a terceira somativa: (a) avaliação inicial, antes da aprendizagem, para detectar as necessidades; (b) avaliação do processo, durante a aprendizagem, para detectar o andamento do processo; (c) avaliação final, depois da aprendizagem, para verificar o cumprimento dos objetivos e avaliar os resultados obtidos. No que diz respeito a esta última, é preciso salientar que não se trata simplesmente de coletar informação ao final do curso; essa informação sobre o estudante pode ser coletada a partir das observações realizadas ao longo do processo de aprendizagem (avaliação contínua);

3. Como se avalia? Três aspectos a esse respeito: as tarefas de avaliação, os resultados da aprendizagem e o dossiê do estudante;

4. Quem avalia? A importância de integrar diferentes olhares avaliativos, fazendo intervir: o professor, o estudante sobre si mesmo (a autoavaliação), os outros estudantes.

Pode-se confirmar que uma competência é adquirida somente quanto ela é posta à prova: trata-se, portanto, de criar tarefas de avaliação que permitam aos estudantes mostrar seu grau de aquisição da competência, e que correspondam a situações da vida profissional (atividades autênticas ou simuladas) ${ }^{28}$. Para tanto, a execução de tarefas integralizadoras de avaliação adquire uma grande importância.

Numerosos são, atualmente, os autores que insistem na importância dos resultados da aprendizagem (cf., por exemplo, Herrington and Herrington, 1998, apud Yániz; Villardón 98). A aprendizagem deve, com efeito, levar à produção de resultados, ou seja, produções do estudante que mostrem que houve aprendizagem. No que diz res-

${ }^{28}$ Cf. Martínez Melis (2001), onde exemplos de tarefas de avaliação são propostos para a didática da tradução na língua estrangeira.

Cad. Trad., Florianópolis, v. 40, $\mathrm{n}^{0}$ 1, p. 367-416, jan-abr, 2020. 
peito à didática da tradução, existem diferentes tipos de resultados: as traduções, as fichas, a documentação utilizada, os relatórios, o diário de tradução, etc. Para se conseguir uma boa avaliação do estudante, é preciso ter em vista a triangulação dos resultados e atentar para a fiabilidade e variedade das produções obtidas.

É nesse contexto que o dossiê do estudante (o portfólio) adquire uma grande importância como instrumento de avaliação, complementar ou integral, consistindo em uma seleção e uma reflexão do estudante sobre suas produções. Esse dossiê é centrado mais nas execuções do que nos conteúdos teóricos. De acordo com Bonsón e Benito (99), os objetivos do dossiê são: (1) melhorar a autorreflexão do estudante sobre sua aprendizagem; (2) estimular a motivação do estudante para a aprendizagem, já que ele pode expressar o esforço e os progressos realizados, atingir objetivos de aprendizagem diferentes e constatar a aplicabilidade de seus conhecimentos; (3) implicar o estudante na avaliação (como autoavaliado e como selecionador de seus trabalhos), centrando-a mais em produções do que em conteúdos; (4) associar a aprendizagem às tarefas profissionais.

\section{c. A avaliação na Introdução à Tradução}

Eis exemplos de tarefas de avaliação para a Introdução à Tradução, para as quais indicamos a competência avaliada entre parênteses.

- Teste de problemas contrastivos (contrastiva);

- Análise de textos paralelos (contrastiva);

- Tradução sintética (metodológica e estratégica);

- Identificação e análise de problemas de tradução (metodológica e estratégica);

- Identificação, análise e correção de erros de tradução (metodológica e estratégica);

- Tradução comentada (uma tradução com comentários sobre os problemas encontrados, as estratégias aplicadas, a docu- 
mentação utilizada, etc.) (textual, metodológica e estratégica, instrumental);

- Tradução justificada ${ }^{29}$ (uma tradução com identificação de problemas e justificação das soluções propostas) (textual, metodológica e estratégica);

- "Diário de tradução" de uma ou várias traduções ou das traduções feitas ao longo do curso. Trata-se de um "diário reflexivo" (Bonsón; Benito 98): um documento pessoal que o estudante elabora periodicamente e que pode compreender observações, sentimentos, reações, interpretações, reflexões, pensamentos, hipóteses e explicações. Esses diários refletem a experiência de aprendizagem do estudante (metodológica e estratégica);

- Relatórios de todo tipo: sobre a elaboração de uma tradução (problemas encontrados, estratégias e documentação empregadas, etc.), etc. (p. ex. instrumental, contrastiva, metodológica e estratégica).

Para a descrição de cada tarefa, é preciso incluir o procedimento (o que os estudantes devem fazer), assim como os instrumentos (textos, fichas, exercícios, baremas, etc.).

No que diz respeito ao dossiê do estudante, considerando que a Introdução à Tradução é uma etapa inicial da formação, ele deveria ser orientado pelo professor. Esse dossiê pode compreender, por exemplo, as seguintes produções do estudante, para as quais indicamos a competência avaliada entre parênteses.

- Catálogo de literalismos (contrastiva);

- Coletânea de dificuldades contrastivas (contrastiva);

- Traduções sintéticas (metodológica e estratégica);

- Seleção de problemas de tradução encontrados (metodológica e estratégica);

- Seleção de erros cometidos (metodológica e estratégica);

${ }^{29}$ N. das T.: no original: Traduction raisonnée. 
- Relatório sobre as ferramentas de documentação mais úteis (instrumental);

- Relatório sobre o mercado de trabalho da tradução (profissional);

- Relatório sobre os referentes culturais mais difíceis de resolver e as soluções possíveis (extralinguística);

- Traduções acompanhadas de um relatório sobre os problemas encontrados, as estratégias e a documentação utilizadas (textual, metodológica e estratégica, instrumental).

Esse dossiê deveria igualmente incluir um relatório de apresentação justificando as escolhas, assim como um relatório final de autoavaliação (ou diário de tradução) sobre os conhecimentos adquiridos.

\section{Conclusão}

Tínhamos iniciado este artigo propondo três grandes desafios pedagógicos que há muito tempo se encontram no âmago da didática da tradução: aprender fazendo, aprender a percorrer processos e aprender de uma maneira holística. Esperamos ter correspondido às expectativas do leitor, pelo menos parcialmente, pois restam ainda várias questões sem resposta. Efetivamente, ainda há muito a se aprender sobre a didática da tradução. Eis, portanto, à guisa de conclusão, o que dizem Yániz e Villardón (2006) como introdução ao seu livro:

Se aprender é mais do que estudar,

Se ensinar é mais do que explicar,

E se é ensinando que se aprende,

Para ensinar é preciso aprender ${ }^{30}$.

30 "Porque aprender es más que estudiar, porque enseñar es más que explicar, porque enseñando se aprende, para enseñar hay que aprender". 


\section{Referências}

Anderson, John R. The Architecture of Cognition. Cambridge: Harvard University Press, 1983.

Beeby, Allison. Teaching Translation from Spanish to English. Ottawa: University of Ottawa Press, 1996.

Bell, Roger T. Translation and Translating. Londres: Longman, 1991.

Biggs, John. Calidad del aprendizaje universitario. Madrid: Narcea, 2005.

Bloom, Benjamin S. et al. Taxonomy of Educational Objectives: Handbook 1: Cognitive Domain. New York: McKay, 1956.

Bonsón, Magdalena; Benito, Agueda. "Evaluación y aprendizaje”. In: Benito, A.; Cruz, A. Nuevas claves para la docencia universitaria. Madrid: Narcea, 2005, p. 87-100.

Borja, Anabel. Estrategias, materiales y recursos para la traducción jurídica. Castellón: Universitat Jaume I, 2007. No prelo.

Boyatzis, Richard E. The Competent Manager: A Model for Effective Performance. New York: Wiley-Interscience, 1982(a).

Boyatzis, Richard E. Identification of Skill Requirements for Effective Job Performance. Boston: McBer, 1984(b).

Brehm, Justine. Targeting the Source Text: A Coursebook in English for Translators Trainees. Castellón: Universitat Jaume I, 2004.

Calvo Encinas, Elisa. "La Administración Pública ante la interpretación social: toma de contacto en la provincia de Toledo". Puentes, [s.1], 7-16, 2004, 4, p. 
Campbell, Stuart. Translation into the Second Language. Londres: Longman, 1998.

Candlin, Christopher; Murphy, David. (Org.). Language Learning Tasks. Englewood Cliffs N.J.: Prentice Hall, 1987.

Chesterman, Andrew. Memes of Translation. Amsterdam: John Benjamins, 1997.

Delisle, Jean. L'analyse du discours comme méthode de traduction. Ottawa: Éditions de l'Université d'Ottawa, 1980(a).

Delisle, Jean. La traduction raisonnée. Manuel d'initiation à la traduction professionnelle de l'anglais vers le français. Ottawa: Éditions de l'Université d'Ottawa, 1993(b).

Dirube, José L. Un modelo de gestión por competencias. Lecciones aprendidas. Barcelone: Gestión 2000, 2004.

Dreyfus, Hubert L.; Dreyfus, Stuart E. Mind over Machine. The Power of Human Intuition and Expertise in the Era of the Computer. Oxford: Blackwell, 1986.

Escotet, Miguel A. Globalización y educación superior: desafíos en una era de incertidumbre. In: III Symposium Iberoamericano de docencia universitaria. Pedagogía universitaria: hacia un espacio de aprendizaje compartido. Anais... Bilbao: Mensajero, 2004, p. 23-35.

Estaire, Sheila; Zanón, Javier. Planning Classwork. A Task-based Approach. Oxford: Heinemann, 1994.

Gamero, Silvia. Traducción alemán-español. Aprendizaje activo de destrezas. Castellón: Universitat Jaume I, 2005.

Golden, Sean; Hurtado Albir, Amparo; Pique, Ramón. La traducció i la interpretació a Catalunya. Noves SL, [s.1], 17, 1992, p. 14-17. 
Gonçalves, José Luiz Vila Real. O desenvolvimento da competência do tradutor: investigando o processo através de um estudo exploratório-experimental. 2003(a). Tese de doutorado, Universidade Federal de Minas Gerais, Belo Horizonte.

Gonçalves, José Luiz Vila Real. O desenvolvimento da competência do tradutor: em busca de parâmetros cognitivos. In: Alves, F.; Magalhães, C.; Pagano, A. (Orgs.). Competência tradutória: cognição e discurso. Belo Horizonte: Editora da UFMG, 2005(b), p. 59-90.

González, Julia; Wagenaar, Robert. Tuning Educational Structures in Europe. Final Report. Phase One. Bilbao: Universidad de Deusto, 2003.

González Davies, María. (Org.). Secuencias. Barcelona: Octaedro, 2003(a).

González Davies, María. Multiple Voices in the Translation Classroom. Amsterdam: John Benjamins, 2004(b).

Hansen, Gyde. "Success in Translation". Perspectives, [s.1], Studies in Translatology, 5, 2, 1997, p. 201-210.

Harris, Brian. "La traductologie, la traduction naturelle, la traduction automatique et la sémantique". Cahiers de linguistique, [s.1], 3, 1973(a), p. 133-146.

Harris, Brian. "The Importance of Natural Translation". Working Papers on Bilingualism, [s.1], 12, 1977(b), p. 96-114.

Harris, Brian. "How a Three-Year-Old Translates". Patterns of Bilingualism, [s.1], National University of Singapore Press, 1980(c), p. 370-393.

Harris, Brian; "Sherwood Bianca. Translating as an Innate Skill”. In: Gerver, D.; Sinaiko, H. W. (Org.). Language, Interpretation and Communication. Oxford: Plenum Press, 1978(d), p. 155-170.

Hermans, Johan ; Lambert, José. "From Translation Markets to Language Management: The Implications of Translation Services". Target, [s.1], 10, 1, 1998, p. 113-132. 
Herrington, Jan; Herrington, Anthony. "Authentic Assessment and Multimedia: How University Students Respond to a Model of Authentic Assessment". Higher Education Research and Development, [s.1], 17, 3, 1998, p. 305-322.

Hurtado Albir, Amparo. "Didactique de la traduction des textes spécialisés". In : Actes de la 3ème Journée ERLA-GLAT. Lexique spécialisé et didactique des langues. Anais... Brest : UBOENST1992(a), p. 9-21.

Hurtado Albir, Amparo. Un nuevo enfoque de la didáctica de la traducción. Metodología y diseño curricular. In : Gauchola, C. Mestreit ; Tost, M. (Org.). Les langues étrangères dans l'Europe de l'Acte Unique. Barceloa : ICE de la Universitat Autònoma de Barcelona, 1993(b), p. 239-252.

Hurtado Albir, Amparo. La enseñanza de la traducción directa "general". Objetivos de aprendizaje y metodología. In: A. Hurtado Albir, (Org.). La enseñanza de la traducción. Castellón: Universitat Jaume I, 1996(c), p. 31-55.

Hurtado Albir, Amparo. (Org.). Enseñar a traducir. Metodología en la formación de traductores e intérpretes. Madrid: Edelsa, 1999(d).

Hurtado Albir, Amparo. Traducción y Traductología. Introducción a la Traductología. Madrid: Cátedra, 2001(e).

Hurtado Albir, Amparo. Competence-based Curriculum Design for Training Translators. The Interpreter and Translator Trainer, 1/2, 2007(f), p. 163-195.

Hutchinson, Tom. Introduction to Project Work. Oxford: Oxford University Press, 1991.

Jääskeläinen, Riitta. What Happens in a Translation Process: Think-Aloud Protocols of Translation. Tese de doutorado, Savonlinna School of Translation Studies, University of Joensuu, 1987(a).

Jääskeläinen, Riitta. "Translation Assignment in Professional Versus NonProfessional Translation: A Think-Aloud Protocol Study". In: Séguinot, C. (Org.). The Translation Process. Toronto: H.G. Publications, York University, 1989(b), p. 87-98. 
Jääskeläinen, Riitta. Tirkkonen-Condit, Sonia. "Automatised Processes in Professional vs. Non-professional Translation: A Think-Aloud Protocol Study". In: Tirkkonen-Condit, S. (Org.). Empirical Research in Translation and Intercultural Studies. Tübingen: Gunter Narr, 1991, p. 89-110.

Kelly, Dorothy. "Un modelo de competencia traductora: bases para el diseño curricular". Puentes, [s.1], 1, 2002(a), p. 9-20.

Kelly, Dorothy. A Handbook for Translator Trainers. Manchester: St Jerome, 2005(b).

Kiraly, Don. Pathways to Translation. Pedagogy and Process. Kent: The Kent State University Press, 1995(a).

Kiraly, Don. A Social Constructivist Approach to Translator Education. Manchester: St Jerome, 2000(b).

Kuznik, Anna. Marco conceptual y metodológico para un estudio sobre las tareas de traducción e interpretación desempeñadas en el ámbito laboral. Travail de recherche. Universitat Autònoma de Barcelona, 2007.

Lasnier, François. Réussir la formation par compétences. Montréal: Guérin, 2000.

Li, Defeng. "Tailoring Translation Programs to Social Needs: A Survey of Professional Translators”. Target, 12, 1, 2000, p. 127-149.

Lorenzo, María Pilar. "La seguridad del traductor profesional en la traducción a una lengua extranjera". In: Hansen, G. (Org.). Probing the Process in Translation: Methods and Results. Copenhague: Samfundslitteratur, 1999, p. 121-134.

Lowe, Pardee. Revising the ACTFL/ETS Scales for a New Purpose: Rating Skill in Translating. In: ROSE, M.G. (Org.) Translation Excellence: Assessment, Achievement, Maintenance. American Translators Association Series, vol. 1. New York: SUNY Binghamton Press, p. 53-61. 1987. 
Mackenzie, Rosemary. "Posi-tive Thinking About Quality in Translator Training in Finland". In: Beeby, A.; Ensinger, D.; Presas, M. (Org.). Investigating Translation. Amsterdam: John Benjamins, 2000, p. 213-222.

Martinez Melis, Nicole. Évaluation et didactique de la traduction: le cas de la traduction dans la langue étrangère. 2001. Tese de doutorado, Universitat Autònoma de Barcelona, Barcelona.

McClelland, David C. "Testing for Competence rather than for Intelligence". American Psychologist, [s.1], 28, 1973, p. 1-14.

Metfesel, Newton S.; Michael, William B.; Kirsner, Donald A. "Instrumentation of Bloom's and Krathwolh's Taxonomies for the Writing of Educational Objectives”. Psychology in the Schools, [s.1], 6, 3, 1969, p. 227-231.

Neubert, Albrecht. "Competence in Language, in Languages, and in Translation". In: Schäffner, C.; Adab, B. (Org.). Developing Translation Competence. Amsterdam: John Benjamins, 2000, p. 3-18.

Nunan, David. Designing Tasks for the Communicative Classroom. Cambridge: Cambridge University Press, 1989.

Orozco, Mariana. Instrumentos de medida de la adquisición de la competencia traductora: Construcción y validación, 2000. Tese de doutorado, Universitat Autònoma de Barcelona, Barcelona.

Ørsted, Jeannette. "Quality and Efficiency: Incompatible Elements in Translation Practice". Meta, [s.1], 46, 2, 2001, p. 438-447.

Pacte. "La competencia traductora y su aprendizaje: objetivos, hipótesis y metodología de un proyecto de investigación". In: IV Congrés Internacional sobre Traducció. Poster. Barcelona: 1998(a).

Pacte. "Acquiring Translation Competence: Hypotheses and Methodological Problems in a Research Project”. In: Beeby, A.; Ensinger, D.; Presas, M. (Org). Investigating Translation. Amsterdam: John Benjamins, 2000(b), p. 99-106. 
Pacte. "Exploratory tests in a study of translation competence". Conference Interpretation and Translation, 4, 2, 2002(c), p. 41-69.

Pacte. "Building a Translation Competence Model". In: ALVES, F. (Org.) Triangulating Translation: Perspectives in Process Oriented Research. Amsterdam: John Benjamins, 2003(d), p. 43-66.

Pacte. "Investigating Translation Competence: Conceptual and Methodological Issues”. Meta, [s.1], 50, 2, 2005(e), p. 609-619.

Pacte. "Une recherche empirique expérimentale sur la compétence en traduction". In: Gouadec, D. (Org.). Actes du Colloque International: quelle formation pour le traducteur?. Anais... Paris : Maison du dictionnaire, 2007(f). No prelo.

Pacte. "First results of a translation competence experiment: 'Knowledge of translation' and 'Efficacy of the translation process'. In: Kearns, J. (Org.) Translator and Interpreter Training: Ideas, Methods and Debates. Londres: Continuum, 2008(g).

Paris, Scott G.; Lipson, Marjorie Y.; Wixson, Karen K. "Becoming a Strategic Reader”. Contemporary Educational Psychology, [s.1], 8, 1983, p. 293-316.

Paris, Scott G.; Cross, David R.; Lipson, Marjorie Y. "Informed Strategies for Learning: A Program to Improve Children's Reading Awareness and Comprehension". Journal of Educational Psychology, [s.1], 76, 1984, p. 12391252.

Piaget, Jean. La psychologie de l'intelligence. Paris: Librairie Armand Collin, 1947.

Pozo, Juan Ignacio; Postigo, Yolanda. "Las estrategias de aprendizaje como contenido del currículo". In: Font, C. Monereo (Org.). Estrategias de aprendizaje . Barcelona: Domènech, 1993, p. 106-112.

Presas, Marisa. Problemes de traducció $i$ competència traductora. Bases per a una pedagogia de la traducció. 1996. Tese de doutorado, Universitat Autònoma de Barcelona, Barcelona. 
Ribe, Ramón; Vidal, Nuria. Project Work, Step by Step. Oxford: Heinemann, 1993.

Risku, Hanna. Translatorische Kompetenz. Kognitive Grundlagen des Übersetzens als Expertentätigkeit. Tübingen: StauMenburg, 1998.

Schraw, Gregory; Moshman, David. "Metacognitive Theories". Educational Psychology Review, [s.1], 7, 4, 1995, p. 351-371.

Séguinot, Candace. "A Study of Student Translation Strategies". In: TirkkonenCondit, S. (Org.). Empirical Research in Translation and Intercultural Studies. Tübingen: Gunter Narr, 1991, p. 79-88.

Shreve, Gregory. "Cognition and the Evolution of Translation Competence". In: Danks, J. H. et al. (Org.). Cognitive Processes in Translation and Interpreting. Thousand Oaks: Sage, 1997, p. 120-136.

Spencer, Lyle M. Jr.; McClelland, David C.; Spencer, Signe M. Competency Assessment Methods: History and State of Art. New York: Hay/McBer Research Press, 1994.

Stansfield, Charles W.; Scott, Mary Lee; Kenyon, Dorry M. "The Measurement of Translation Ability". The Modern Language Journal, [s.1], 76, 4, 1992, p. 455-467.

Tirkkonen-Condit, Sonia. "Professional vs. Non-Professional Translation: A Think-Aloud Protocol Study". In: Halliday, M. A. K.; Gibbons, J.; Nicholas, H. (Org.). Learning, Keeping and Using Language. Amsterdam: John Benjamins, 1990, p. 381-394.

Toury, Gideon. Descriptive Translation Studies and Beyond. Amsterdam: John Benjamins, 1995.

Vygotsky, Lev S. Pensée et langage. Paris: Éditions sociales, 1984 (1934).

Wellington, Jerry J. Skills and Processes in Science Education. A Critical Analysis. Londres: Routledge, 1989. 
Willis, Jane D. A Framework for Task-Based Learning. Oxford: Longman, 1996.

Yáníz, Concepción; Villardón, Lourdes. Planificar desde competencias para promover el aprendizaje. Bilbao: Universidad de Deusto, 2006.

Zanón, Javier. Los enfoques por tareas para la enseñanza de las lenguas extranjeras. Cable, 5, 1990, p. 19-27.

Recebido em: 20/08/2019

Aceito em: 31/11/2019

Publicado em janeiro de 2020

Amparo Hurtado Albir. Professora da Faculdade de Tradução e Interpretação da Universidade Autônoma de Barcelona (UAB); coordenadora do grupo de pesquisa PACTE (grupsderecerca.uab.cat/pacte/). (N. das T) E-mail: amparo.hurtado@ uab.es

ORCID: https://orcid.org/0000-0002-4362-7183

Lavínia Teixeira Gomes. E-mail: lavinia.teixeira.gomes@gmail.com

ORCID: https://orcid.org/0000-0002-1469-6155

Marta Pragana Dantas. E-mail: praganamarta@yahoo.fr

ORCID: https://orcid.org/0000-0002-0343-9540 